\title{
Transtorno obsessivo-compulsivo
}

\author{
Christina Hajaj Gonzalez
}

\section{Resumo}

O transtorno obsessivo-compulsivo (TOC) é um quadro psiquiátrico caracterizado pela presença de obsessões e compulsões. Sua prevalência é de aproximadamente $2 \%$ a 3\% na população geral. Os fatores genéticos estão provavelmente implicados na etiologia do transtorno. Os estudos realizados sugerem que há diferentes subtipos de TOC: TOC com história familiar positiva para TOC, TOC "esporádico" e TOC associado com a tiques. Os estudos de gêmeos mostram uma alta concordância de TOC entre gêmeos monozigóticos. Em alguns estudos de famílias observou-se um maior risco para TOC entre os familiares de pacientes com TOC. Os estudos de análise de segregação sugerem o envolvimento de um gene de efeito maior na etiologia do transtorno. Através de estudos moleculares, diferentes grupos de pesquisadores vêm tentando a localizar um possível gene envolvido na etiologia do TOC.

\section{Descritores}

Transtorno obsessivo-compulsivo (TOC); genética; transtorno de Tourette; tiques

\begin{abstract}
Obsessive-compulsive disorder (OCD) is a psychiatric condition characterized by the presence of obsessions and compulsions. Its prevalence in the general population is around 2 to $3 \%$. Genetic factors are probably involved in its etiology. Studies suggest there are different subtypes of OCD: OCD with a positive family history of OCD, sporadic OCD, and OCD related to tics. Twin studies show a high concordance rate for monozygotic twins. Some of the family studies observed a higher risk for OCD among relatives of OCD patients. Segregation analysis studies suggest the possible role of a major gene effect in the etiology of the disorder. By means of molecular studies, several investigators have been trying to find a gene involved in the etiology of OCD.
\end{abstract}

\section{Keywords}

Obsessive-compulsive disorder (OCD); genetics; Tourette's syndrome; tics

\section{Introdução}

O transtorno obsessivo-compulsivo (TOC) é caracterizado pela presença de obsessões e compulsões. Obsessões são idéias, pensamentos, imagens ou impulsos repetitivos e persistentes que são vivenciados como intrusivos e provocam ansiedade. Não são apenas preocupações excessivas em relação a problemas cotidianos. A pessoa tenta ignorá-los, suprimi-los ou neutralizá-los através de um outro pensamento ou ação. Compulsões são comportamentos repetitivos ou atos mentais que visam reduzir a ansiedade e afastar as obsessões. Esses rituais freqüentemente são percebidos como algo sem sentido e o indivíduo reconhece que seu comportamento é irracional. Geralmente a pessoa realiza uma compulsão para reduzir o sofrimento causado por uma obsessão. As obsessões mais comuns são: preocupação com sujeira ou secreções corporais, medo de que algo terrível possa acontecer a si mesmo ou a alguém querido, preocupação com simetria e escrupulosidade. As principais compulsões são: lavagem de mãos, verificação de portas, ordenação e arrumação, contagem e colecionismo. ${ }^{1}$ Para se fa- zer um diagnóstico de TOC é necessário que o nível da sintomatologia interfira no funcionamento social, interpessoal, ocupacional ou acadêmico do indivíduo e que os sintomas ocupem mais de uma hora por dia. ${ }^{2}$

A prevalência do TOC ao longo da vida na população geral varia de $2 \%$ a $3 \%$ e a prevalência anual é de $1,5 \%$. Os sintomas têm início na infância ou na adolescência em um terço a metade dos casos. A distribuição entre os sexos é semelhante, sendo discretamente maior entre as mulheres.

Um dos principais fatores associado à etiologia do TOC é a hereditariedade. São propostos três fenótipos possíveis para o TOC: TOC "esporádico", TOC com história familiar positiva e TOC associado a tiques. ${ }^{5}$

O transtorno de Tourette (TT) é caracterizado pela presença de múltiplos tiques motores crônicos e ao menos um tique vocal, com duração mínima de um ano e aparecimento antes dos 18 anos. Vários estudos demonstraram que o TT tem etiologia genética, com padrão de transmissão familiar autossômico dominante e penetrância variável de acordo com o sexo: $99 \%$ no 
sexo masculino e $70 \%$ no sexo feminino. Dos pacientes com TOC, até $15 \%$ têm transtorno de Tourette e dos pacientes com Transtorno de Tourette, $20 \%$ a $60 \%$ têm sintomas obsessivos e compulsivos. ${ }^{6,7}$

\section{Estudos de gêmeos}

O método de estudo de gêmeos consiste em comparar o número de pares de gêmeos monozigóticos (MZ) nos quais os dois indivíduos são afetados pela mesma doença com o número de pares de gêmeos dizigóticos (DZ) em que os dois indivíduos são afetados. O material genético dos gêmeos MZé idêntico. Portanto diferenças entre os indivíduos são devidas a mutações genéticas ou a diferentes influências ambientais ou de desenvolvimento. Gêmeos DZ têm a mesma proximidade genética apresentada por irmãos nascidos em épocas diferentes. As diferenças entre esses indivíduos são atribuídas tanto a fatores genéticos quanto a fatores ambientais. Numa revisão da literatura realizada por Rasmussen e Tsuang, ${ }^{8}$ foi encontrada uma concordância de $63 \%$ de TOC em 51 pares de gêmeos MZ. A taxa de concordância de TOC entre gêmeos DZ é de aproximadamente $22 \% .{ }^{9}$ Em um estudo onde se ampliou o diagnóstico englobando-se TOC e pacientes com sintomas obsessivos e compulsivos que não preenchiam critérios diagnósticos para TOC, foi observada uma taxa de concordância de $87 \%$ para gêmeos $\mathrm{MZ}$ contra $47 \%$ para gêmeos DZ. ${ }^{9}$

Até o presente, não foram relatados estudos de adoção.

\section{Estudos de famílias}

Nos estudos de famílias são comparadas as taxas de freqüência de uma doença entre os familiares de um indivíduo afetado pela doença (probando) com as taxas de frequiência desta doença entre os familiares de indivíduos não afetados (controles). Os dados dos trabalhos realizados nesta área sugerem que há uma maior prevalência de TOC, sintomas obsessivo-compulsivos, TT e Transtorno de Tique Motor ou Vocal Crônico entre os familiares de pacientes com TOC.

Estudando os parentes de $1^{\circ}$ grau de 46 crianças e adolescentes com TOC, Lenane et al. ${ }^{10}$ encontraram um risco mórbido de TOC e TOC subclínico (indivíduos com sintomas obsessivos e compulsivos que não preenchiam critérios diagnósticos de TOC) de $35 \%$, sendo que $25 \%$ dos pais, $9 \%$ das mães e $5 \%$ dos irmãos apresentavam TOC. Entrevistando os pais de 21 crianças e adolescentes com TOC, Riddle et al. ${ }^{11}$ observaram a presença de TOC e TOC subclínico em $35,7 \%$ destes. Bellodi et al. ${ }^{12}$ observaram apenas $3,4 \%$ de TOC entre os parentes de $1^{\circ}$ grau de 92 pacientes com TOC, mas o risco mórbido foi de $8,8 \%$ quando se consideraram apenas os pacientes com idade de início do TOC inferior a 14 anos. Treze por cento dos parentes de $1^{\circ}$ grau de probandos com TOC de início na infância preenchiam critérios diagnósticos para TOC em estudo realizado por Leonard et al. ${ }^{13}$ Black et al. ${ }^{14}$ estudaram os familiares de 32 probandos com TOC e de 33 controles sadios. Não foi encontrado maior risco mórbido para TOC entre os familiares dos probandos $(2,6 \%)$ quando comparado com o grupo controle $(2,4 \%)$. Quando foram incluídos parentes que tinham sintomas obsessivos e compulsivos e que não preenchiam critérios diagnósticos para TOC, o risco foi maior nos parentes dos probandos do que nos parentes dos controles sadios (16\% versus $3 \%$, respectivamente). Pauls et al. ${ }^{5}$ estudaram com entrevistas psiquiátricas estruturadas parentes de $1^{\circ}$ grau de 100 probandos com TOC $(n=466)$ e 133 parentes (controles) de $1^{\circ}$ grau de 33 indivíduos sadios. Observaram $10,9 \%$ de TOC e 7,9\% de TOC subclínico nos parentes de $1^{\circ}$ grau dos probandos. Entre os controles, as taxas foram de $1,9 \%$ de TOC e 2,0\% de TOC subclínico. Os autores também observaram uma diferença estatisticamente significante nas taxas de Transtornos de Tiques (transtorno de Tourette e transtorno de tique motor ou vocal crônico) nos parentes dos probandos quando comparados aos controles: $4,6 \%$ e $1,0 \%$, respectivamente.

Em nosso meio, ${ }^{15}$ observamos uma prevalência de $6,9 \%$ de TOC entre 173 parentes de $1^{\circ}$ grau de 30 probandos com TOC e $1,4 \%$ de TOC entre os controles $(n=348)$. Observamos também prevalência de $19,1 \%$ de sintomas obsessivos e compulsivos entre os parentes dos pacientes com TOC e 3,2\% desses sintomas entre os controles.

\section{Estudos de análise de segregação}

Nos estudos de análise de segregação, famílias de pacientes com uma doença são estudadas para se entender se ela transmite de uma geração para outra. O modo de transmissão da doença num determinado grupo de famílias é estudado e é comparado com modelos teóricos para se saber qual o modelo que melhor se ajusta aos dados obtidos.

Nicolini et al. ${ }^{16}$ realizaram um estudo com 24 famílias de pacientes com TOC em que 11 pacientes tinham história familiar positiva para TOC. Não foi possível se excluir um modelo de transmissão autossômica recessiva ou dominante, porém o modelo mais compatível e provável foi o de transmissão autossômica dominante com penetrância de $80 \%$.

Os padrões de transmissão de 107 famílias de pacientes com TOC dos quais 29 também apresentavam TT ou Transtorno de Tiques Motores ou Vocais Crônico foram estudados por Cavalini et al. ${ }^{17}$ Concluíram que o modelo de transmissão mais compatível seria o autossômico dominante com penetrância maior nas mulheres.

Os estudos de segregação indicam o possível envolvimento de um gene de efeito maior na suscetibilidade ao TOC.

\section{Estudos de associação}

Nos estudos de associação observa-se a freqüência de um gene ou de um determinado polimorfismo no grupo de afetados e compara-se com um grupo de controles não afetados. Nos últimos anos, alguns genes de receptores serotoninérgicos e dopaminérgicos têm sido investigados, uma vez que esses neurotransmissores são os que apresentam uma provável implicação na fisiopatologia do TOC.

Pacientes tratados com inibidores seletivos da recaptação de serotonina (clomipramina, fluoxetina e fluvoxamina) têm uma significativa redução nos sintomas quando comparados com aqueles tratados com outros antidepressivos que não têm efeito específico sobre a recaptação de serotonina (5HT). ${ }^{18}$

A dopamina também tem sido estudada no TOC, uma vez que 
medicações neurolépticas (antagonistas de receptores dopaminérgicos), como a pimozida e o haloperidol, são eficazes no tratamento de tiques, freqüentes entre os pacientes com TOC.

\section{Genes do sistema serotoninérgico}

Foram realizados alguns estudos para investigar a possível associação entre os genes ligados à transmissão serotoninérgica e o TOC.

O gene que codifica a proteína do transportador da 5HT (5HTT) é candidato à investigação molecular no TOC, uma vez que o 5HTT tem um papel importante na mediação do processo de recaptura de $5 \mathrm{HT}$ na terminação neural pré-sináptica. Uma alteração na estrutura do gene do 5HTT poderia explicar uma suscetibilidade ao TOC. Dois estudos investigaram o gene 5HTT e não foram observadas alterações na estrutura primária da região que codifica o gene e no polimorfismo, caracterizado por uma inserção ou deleção de 44 pares-de-base (pb), localizado na região promotora do gene. ${ }^{19,20}$

McDougle et al. ${ }^{21}$ investigaram o polimorfismo SLC6A4 da região promotora do gene 5HTT que afeta a expressão da proteína e está associado com medidas de ansiedade e depressão e autismo. Foi utilizado o teste de desequilíbrio de ligação (TDT) em 34 trios de famílias (paciente, pai e mãe) para se testar o possível desequilíbrio de ligação entre TOC e os alelos no lócus polimórfico SLC6A4. Os resultados desse estudo sugerem que há evidências da associação entre o desequilíbrio de ligação do alelo "l" do SLC6A4 e o TOC.

O polimorfismo T102C do gene do receptor 5HT2A foi estudado por Nicolini et al $^{22}$ Não foram encontradas diferenças entre os grupos de pacientes e controles.

Um outro polimorfismo do gene do receptor 5HT2A, o-1438G/ A da região promotora do gene, foi investigado por Hino et al. ${ }^{23}$ Observou-se um aumento não significante da frequiência do alelo -1438A no grupo de pacientes quando comparado com o grupo controle.

Cavalini et $\mathrm{al}^{24}$ estudaram a associação entre o polimorfismo caracterizado por uma mutação de 1 bp Cys23-Ser23 no gene do receptor 5HT2C localizado no cromossomo X e o TOC. Não foi observada associação entre TOC e a freqüência da mutação do $5 \mathrm{HT} 2 \mathrm{C}$.

\section{Genes do sistema dopaminérgico}

Evidências baseadas em estudos clínicos, de imagem e genéticos sugerem a ligação entre TOC e tiques. Os tiques e o TT têm na sua fisiopatologia uma provável disfunção dopaminérgica. Com a recente identificação de diversos genes de receptores dopaminérgicos, estudos moleculares têm sido realizados para se conhecer a participação desses genes na suscetibilidade ao TOC.

Novelli et al. ${ }^{25}$ estudaram três exons (4, 5 e 6$)$ do gene do receptor dopaminérgico D2 (DRD2) e não observaram alterações na estrutura molecular dos exons, sugerindo não haver relação entre alterações no DRD2 e TOC.

Após o relato de associação entre TT e homozigose para o polimorfismo localizado no primeiro exon do gene do receptor dopaminérgico D3 (DRD3), ${ }^{26}$ Catalano et al. ${ }^{27}$ investigaram a possível associação entre esse polimorfismo e TOC. Os resultados indicam que a homozigose no lócus polimórfico MscI do DRD3 não confere suscetibilidade ao TOC.

Uma mutação nula no primeiro exon do receptor dopaminérgico D4 (DRD4), caracterizada pela deleção de 13 bp e que codifica um receptor truncado, não funcionante, foi estudada por Di Bella et al. ${ }^{28}$ Os resultados observados excluíram a participação desta mutação na patogenia do TOC.

Nicolini et al. ${ }^{22}$ estudaram os polimorfismos TaqI-A do gene DRD2 e MscI do gene DRD3 em pacientes com TOC e controles. Não observaram diferenças estatisticamente significantes nas freqüências genotípicas ou alélicas dos polimorfismos entre os grupos. Porém, quando compararam os pacientes com TOC mais tiques crônicos com o grupo controle, encontraram uma tendência à homozigose para o genótipo A2A2 do locus polimórfico TaqI-A do DRD2 entre os pacientes com TOC mais tiques. Esses dados sugerem que o grupo de indivíduos afetado por TOC e tiques deve representar um subtipo genético diferente do transtorno.

Outros dois trabalhos também relataram diferenças entre pacientes com TOC e tiques e pacientes com TOC sem tiques. Cruz et al $^{29}$ estudaram uma região hipervariável no terceiro exon do gene DRD4, polimorfismo caracterizado por um número variável de repetições de 48bp (VNTR - Variable Number of Tandem Repeats), em 61 pacientes com TOC (12 com tiques e 49 sem tiques) e 35 controles sem TOC. Os resultados sugerem que as variações genotípicas do DRD4 poderiam contribuir para uma variabilidade no fenótipo do TOC com e sem tiques. Nicolini et al. ${ }^{30}$ relataram diferenças entre pacientes com e sem tiques em estudo de associação entre TOC e os polimorfismos TaqI-A do DRD2 e VNTR do DRD4. Esses resultados reforçam a hipótese de subtipo genéticos diferentes nos afetados por TOC com e sem tiques.

Indivíduos com microdeleções $22 q 11$ podem manifestar alguns transtornos psiquiátricos, incluindo Esquizofrenia e TOC. Portanto, é provável que o lócus 22q11 contenha algum gene que confere susceptibilidade ao TOC. O gene que codifica a enzima catecol-O-metiltransferase (COMT) localiza-se na região 22q11 e uma vez que esta enzima está envolvida na inativação das catecolaminas, incluindo a dopamina, o gene da COMT torna-se um candidato para estudos moleculares do TOC. Karayiorgou et al. ${ }^{31}$ genotiparam 73 pacientes com TOC (42 do sexo masculino e 31 do sexo feminino) e 148 controles pareados quanto ao gene da COMT. Foi utilizado o $P C R$ para identificar um polimorfismo caracterizado por uma substituição de uma valina por uma metionina no códon 158. Esse polimorfismo do gene da COMT leva a uma variação de 3 a 4 vezes na atividade da enzima, sendo que a presença de uma valina determina alta atividade (alelo $\mathrm{H}$ ) e a presença de uma metionina leva à baixa atividade (alelo L). Os autores concluíram que existe associação entre a atividade da COMT em indivíduos do sexo masculino com TOC, o mesmo não ocorrendo nas mulheres. Observaram também associação entre o genótipo L/L e TOC, indicando ser esse um fator de risco para o desenvolvimento do transtorno.

Billiett et al. ${ }^{32}$ genotiparam pacientes com TOC e controles 
pareados para 4 diferentes loci: uma repetição de 40bp no gene do transportador da dopamina, o polimorfismo TaqI-A do DRD2, o polimorfismo MscI do DRD3 e a repetição de 48bp do DRD4. A única diferença observada pelos autores foi na freqüência dos alelos do DRD4, comparando pacientes e controles.

Diferentes grupos de pesquisadores vêm se dedicando a es

\section{Referências bibliográficas}

1. Rapoport J. The neurobiology of obsessive-compulsive disorder. JAMA 1988;260:2888.

2. DSM-IV: Manual Diagnóstico e Estatístico de Transtornos Mentais. $4^{a}$ ed. Porto Alegre: Artes Médicas; 1995

3. Robins LN, Helver JE, Weissman MM. Lifetime prevalence of specific psychiatric disorders in three sites. Arch Gen Psychiatry 1984;41:958-67.

4. Karno M, Golding J, Sorensen S, Burnam A. The epidemiology of obsessive-compulsive disorder in five US communities. Arch Gen Psychiatry 1988;45:1094-99.

5. Pauls DL, Alsobrook II JP, Goodman W, Rasmussen S, Leckman JF. A family study of obsessive-compulsive disorder. Am J Psychiatry 1995;152:76-84.

6. Coffey BJ, Miguel EC, Savage CR, Ranch SL. Tourette's disorder and related problems: a review and update. Harvard Rev Psychiatry 1994;2:121-32.

7. Robertson M. The Gilles de la Tourette syndrome: the current status. Brit J Psychiatry 1989;154:147-69.

8. Rasmussen SA, Tsuang MT. Clinical caracteristics and familiy history in DSM-III obsessive-compulsive disorder. Am J Psychiatry 1986;143: 317-22.

9. Carey G, Gottesman II. Twin and family studies of anxiety, phobic and obsessive disorders. In: Klien DF, Rabkin J, editors. Anxiety: new research and changing concepts. New York: Raven Press; 1981. p.117-36.

10. Lenane MC, Swedo SE, Leonard H, Pauls DL, Sceery W, Rapoport J. Psychiatric disorders in first-degree relatives of children and adolescent with obsessive-compulsive disorder. J Am Acad Child Adolesc Psychiatry 1990;29:407-12.

11. Riddle MA, Scahill L, King R, Hardin MT, Towbin KE, Ort SI, et al. Obsessive-compulsive disorder in children and adolescents: phenomenology and family history. J Am Acad Child Adolesc Psychiatry 1990;29:766-72.

12. Belodi L, Sciuto G, Diaferia G, Ronchi P, Smeraldi E. Psychiatric disorders in the families of patients with obsessive-compulsive disorder. Psychiatry Res 1992;42:111-20.

13. Leonard HL, Lenane MC, Swedo SE, Rettew DC, Gershon ES, Rapoport JL: Tics and Tourette's disorder: a 2-to 7-year follow-up of 54 obsessive-compulsive children. Am J Psychiatry 1992;149:1244-51.

14. Black DW, Noyes R, Goldstein LB, Blum N. A family study of obsessive-compulsive disorder. Arch Gen Psychiatry 1992;49:3628.

15. Gonzalez CH, Miranda MA, Del Porto JA: Estudo Familiar do Transtorno Obsessivo-Compulsivo. Pesquisa em andamento.

16. Nicolini H, Hanna G, Baxter L, Schwartz J, Weissbacker K, Spence MA. Segregation analysis of obsessive-compulsive and related disorders. Preliminary results. Ursus Med 1991;1:25-8.

17. Cavalini MC, Pasquale L, Bellodi L, Smeraldi E. Complex segregation analysis for obsessive-compulsive disorder and related disorders. Am J Med Genet 1999;88:38-43. tudos de genética no TOC para uma melhor compreensão dacontribuição genética na etiologia do transtorno. Até o momento, poucos são os achados positivos e mais avanços são necessários para um melhor entendimento dos diferentes mecanismos na patogênese da doença.

\section{Agradecimentos}

Trabalho realizado com apoio da Fapesp (processo no 97/2553-2).
18. Rapoport J. Recent development in obsessive-compulsive disorder. Neuropsychopharmacology 1991;59:1-10.

19. Altemus M, Murphy DL, Greenberg B, Lesch KP. Intact coding region of the serotonin transporter gene in obsessive-compulsive disorder. Am J Med Genet 1996;67:409-11.

20. Billiett EA, Richter MA, King N, Heils A, Lesch KP, Kennedy JL. Obsessive-compulsive disorder, response to serotonin reuptake inhibitors and the serotonin transporter gene. Mol Psychiatry 1997;2:403-6

21. McDougle CJ, Epperson CN, Price LH, Gelernter J. Evidence for linkage disequilibrium between serotonin transporter gene (SLC6A4) and obsessive-compulsive disorder. Mol Psychiatry 1998;3:270-3.

22. Nicolini H, Cruz C, Camarena B, Orozco B, Kennedy JL, King N, et al. DRD2, DRD3 and 5HT2A receptor genes polymorphisms in obsessive-compulsive disorder. Mol Psychiatry 1996;1:461-5.

23. Enoch MA, Kaye WH, Rotondo A, Greenberg BD, Murphy DL, Goldman D. 5HT2A promoter polymorphism -1438G/A, anorexia nervosa, and obsessive-compulsive disorder. Lancet 1998;351:1785-6

24. Cavalini MC, Di Bella D, Pasquale L, Henin M, Bellodi L. 5HT2C CYS23/SER23 polymorphism is not associated with obsessivecompulsive disorder. Psychiatry Res 1998;77:97-104.

25. Novelli E, Nobile M, Diaferia G, Sciuto G, Catalano M. A molecular investigation suggests no relationship between obsessivecompulsive disorder and the dopamine D2 receptor. Neurophychobiology 1994;29:61-3.

26. Comings DE, Muhleman D, Dietz G, Dino M, LeGro R, Gade R. Association between Tourette's syndrome and homozygosity at the dopamine D3 receptor gene. Lancet 1993;341:906.

27. Catalano M, Sciuto G, Di Bella D, Novelli E, Nobile M, Bellodi L. Lack of association between obsessive-compulsive disorder and the dopamine D3 receptor gene: some preliminary considerations. Am J Med Genet 1994;54:253-5.

28. Di Bella D, Catalano M, Cichon S, Nothen MM. Association study of a null mutation in the dopamine D4 receptor gene in Italian patients with obsessive-compulsive disorder, bipolar mood disorder and schizophrenia. Psychiatr Genet 1996;6:119-21.

29. Cruz C, Camarena B, King N, Páez F, Sidenberg D, Fuente JR, et al. Increased prevalence of the seven-repeat variant of the dopamine D4 receptor gene in patients with obsessive-compulsive disorder with tics. Neurosci Lett 1997;231:1-4.

30. Nicolini H, Cruz C, Páez F, Camarena B. Los genes de los receptores a dopamina D2 y D4 distinguen la presencia clínica de tics en el trastorno obsesivo-compulsivo. Gac Med Mex 1998;134:521-7.

31. Karayiorgou M, Altemus M, Galke BL, Goldman D, Murphy DL, Ott J, et al. Genotype determining low catecol-O-methyltransferase activity as a risk factor for obsessive-compulsive disorder. Proc Natl Acad Sci USA 1997;94:4572-5.

32. Billiett EA, Richter MA, Sam F, Swinson RP, Dai XY, King N, et al. Investigation of dopamine system genes in obsessive-compulsive disoreder. Psychiatr Genet 1998;8:163-9.

\section{Correspondência: Christina Hajaj Gonzalez}

Departamento de Psiquiatria da Universidade Federal de São Paulo/Escola Paulista de Medicina

Rua Botucatu. 740 - $3^{\circ}$ andar 04023-900 Vila Clementino São Paulo, SP 